\title{
MEDIATION EFFECT OF AGGRESSIVE BEHAVIOR ON THE CONNECTION BETWEEN TRAIT FORGIVENESS AND INTERPERSONAL RELATIONSHIP
}

\author{
Xiaofeng Yang ${ }^{1 *}$, Wei $\mathrm{Li}^{2}$ \\ ${ }^{1}$ Associate Prof. Dr. Mr., Inner Mongolia Normal University, PR China, steveyangxf@hotmail.com \\ ${ }^{2}$ Associate Prof. Dr. Mrs., Inner Mongolia Normal University, PR China, lily2669@hotmail.com \\ ${ }^{*}$ Corresponding author
}

\begin{abstract}
Interest in forgiveness has explored in recent years as researchers and clinicians began to recognize its value for maintaining emotional well-being, physical health, and healthy intimate relationships. Individuals who tend to adopt forgiving rather than revengeful strategies generally have less aggressive behaviors and better interpersonal relationships with others. We hypothesized that an individual's interpersonal relationship could be predicted by his/her trait forgiveness and aggressive behavior. We tested this hypothesis using a survey, in which five hundred and thirty-eight college students (195 males and 343 females) from five universities in China were investigated with Trait Forgiveness Scale (TFS), Interpersonal Disturbance Scale (IDS), Social-support Scale (SS) and Aggression Questionnaire (AQ). Descriptive statistics and inferential statistics were adopted to analyse the data of survey with SPSS 21. Results indicated that (a) significant gender difference existed in trait forgiveness, that is, trait forgiveness of female students was significantly higher than that of male students $(t=-2.252, p<0.05)$; (b) trait forgiveness positively correlated with social support $(r=0.27, p<0.001)$, and negatively correlated with interpersonal disturbance $(r=-0.35, p<0.001)$ and aggressive behaviors ( $r=-0.40, p<0.001)$; (c) trait forgiveness was the best predictor of interpersonal relationship; (d) aggressive behavior served as a partial mediator variable between trait forgiveness and interpersonal relationship. These results imply that although trait forgiveness and aggressive behavior both affect an individual's interpersonal relationship, the affecting paths were different. Trait forgiveness may directly affect interpersonal relationship, or indirectly through aggressive behavior.
\end{abstract}

Keywords: trait forgiveness, interpersonal relationship, aggressive behavior, mediation effect

\section{INTRODUCTION}

An interpersonal relationship is a strong, deep, or close association or acquaintance between two or more people, which is based on communication, interactions, or some other type of social commitment and is the basis of social groups and society as a whole. Interpersonal relationships often yield good outcomes, such as companionship, security, and social support, though sometimes they are challenged by serious conflicts (Karremans, Van Lange, Ouwerkerk, \& Kluwer, 2003), which may result in anger, resentment, hurt and other negative feelings creating cycles of hostility and desire for revenge. In the face of hurt, whether or not the offended will be able to forgive the offender and avoid negative emotions such as anger and hostility, is essential for the establishment of good interpersonal relationship.

As a construct that may maintain interpersonal relationships and contribute to well-being, FORGIVENESS, in recent years, has received increasing attention (McCullough, Pargament, \& Thoresen, 2000; Watkins et al., 2011). Forgiveness can be regarded as a response to a specific interpersonal hurt or transgression 
perpetrated by another. When the offended forgives, his/her thoughts, feelings and behaviors toward the offender become less negative and more positive. Meanwhile, his/her motivations to avoid and/or seek revenge against the offender are replaced with a motivation to maintain a positive relationship (McCullough et al., 2000). In addition, forgiveness can also be conceptualized as a personality trait, which can be characterized along a forgiving-unforgiving continuum (Berry, Worthington, Parrott, O Connor, \& Wade, 2001; Brose, Rye, Lutz-Zois, \& Ross, 2005; McCullough \& Witvliet, 2002). Individuals who possess such trait may be accustomed to choosing forgiving others as their habitual response to interpersonal transgressions across the time and situations. By forgiving each other, people can move beyond desires for revenge and restore benevolent and harmonious interpersonal relations (McCullough et al., 1998; McCullough, Worthington, \& Rachal, 1997; Tse \& Yip, 2009; Watkins et al., 2011).

Aggression, an important research field in psychology and a common social phenomenon on campus, is overt, often harmful, social interaction with the intention of inflicting damage or other unpleasantness upon another individual (de Almeida, Cabral, \& Narvaes, 2015). Although some scholars has questioned psychological conceptualizations of aggression as universally negative and thought it had some adaptive benefits (Ferguson \& Beaver, 2009), aggressive behaviors, in most cases, might be associated with maladjustment for both aggressors and victims (Card \& Little, 2006; Hawley, Little, \& Card, 2007). Interpersonal relationship and even life safety might be threatened by aggressive behaviors. Indeed, empirical evidence has accumulated over the past decades suggesting personality is one of the most important factors that lead to aggressive behaviors. Neuroticism is positively associated, while agreeableness, openness and conscientiousness are negatively associated, with physical aggression among undergraduate students (Barlett \& Anderson, 2012; Sharpe \& Desai, 2001; Yu, Lim, \& Gamble, 2016).

Taking the close connections of these three psychological constructs into consideration, the present study assumes that aggressive behavior may serve as a mediator between trait forgiveness and interpersonal relationship. The exploring of the relationship between the variables among Chinese undergraduates will, thus, make a unique contribution to the literature.

\section{METHOD}

\subsection{Participants and Procedure}

A sample of 538 college students (195 men and 343 women) with a mean age of 20.04 years ( $S D=1.37$ ) participated in the study. Students from five universities of three cities in China, namely Hohhot, Beijing and Guangzhou, were drawn as a convenience sample. The students were told by the instructors to participate in the study voluntarily without receiving any extra credit and to complete the scales anonymously in class. Measures of forgiveness, aggression and interpersonal relationship were completed as part of a standard intake battery of assessments. All participants were treated in accordance with the ethical guidelines of the American Psychological Association.

\subsection{Measures}

\subsubsection{Trait Forgiveness Scale (Yang, 2019)}

This 8-item scale measures two dimensions of trait forgiveness: tendency to forgive (TF) and tendency to revenge (TR). Each subscale has four items. The scale was developed on the basis of previous literature review, open questionnaire survey and individual interviews done with college students. Respondents are required to rate the items on a 7-point Likert scale ranging from 1 (strongly disagree) to 7 (strongly agree). The TFS has shown acceptable internal consistency (TF: $\alpha=0.74$; TR: $\alpha=0.75$ ) and test-retest reliability (TF: $r s=0.71$; TR: $r s=0.74$ for 4 weeks intervals). The TFS has also shown acceptable construct validity supported by confirmatory factor analysis and convergent and divergent correlations with other measures of forgiveness and related constructs.

\subsubsection{Aggression Questionnaire (Buss \& Perry, 1992)}

This 29-item questionnaire is used to measure individual's aggression behaviors. Respondents are required to rank certain statements along a 5-point continuum from 1 (extremely uncharacteristic of me) to 5 (extremely characteristic of me). The questionnaire returns scores for 4 dimensions of aggression: Physical Aggression, Verbal Aggression, Anger and Hostility. Due to the low internal consistency $(\alpha=0.43)$, the items in Verbal Aggression were deleted in present study. The internal consistency of total scale and other three subscales are adequate (Cronbach $\alpha=0.68 \sim 0.85$ ).

\subsubsection{Perceived Social Support Scale}


The scale is used as a brief self-report measure of subjectively assessed social support in which 12-item ratings were made on a 7-point Likert-type scale ranging from 1 (very strongly disagree) to 7 (very strongly agree), which was originally developed by Zimet et al (1990) and translated into Chines by Jiang (Wang, Wang, \& Ma, 1999). The 12-item scale was designed to measure the perceived adequacy of support from the following three sources: family, friends and significant others. Each subscale includes 4 items and the total score of PSSS is the sum of the three subscales. The higher score the participant gets, the more social support he/she can perceive. The internal consistency of total scale and other three subscales are adequate (Cronbach $\alpha=0.92,0.82,0.88$ and 0.82 , respectively) in present study.

\subsubsection{Interpersonal Disturbance Scale (Zheng, 1999).}

The 28-item scale is a diagnostic measure for interpersonal problematic behaviors. Each item should be responded with "yes" (1 point) or "no" (0 point). The higher score the participant gets, the more interpersonal disturbance he is suffering from. The internal consistency of the scale is acceptable (Cronbach $\alpha=0.83$ ) in present study.

\section{RESULTS}

\subsection{Independent Sample T-test}

The study firstly examined whether there was any difference in demographic variables. Independent sample T-test showed that trait forgiveness of female students was significantly higher than that of male students $(t=$ $-2.25, p<0.05)$.

Then, according to the score of trait forgiveness, the respondents were divided into two groups: high score group (the first 27\%) and low score group (the last $27 \%$ ). Independent sample T-test was used to compare the differences in interpersonal relationship between two groups. Results showed that significant differences existed in social support $(t=-6.07, p<0.001)$ and interpersonal disturbance $(t=8.64, p<0.001)$. The individual who has higher score of trait forgiveness will have more social support and less interpersonal disturbance.

\subsection{Partial Correlation Analysis}

Considering the demographic variables may interact with trait forgiveness, in turn, impact on interpersonal relationship, the study adopted partial correlation analysis to examine the association between trait forgiveness and interpersonal relationship under the premise of controlling demographic variables. Results showed trait forgiveness was positively correlated with social support $(r=0.28, p<0.001)$ and negatively with interpersonal disturbance $(r=-0.37, p<0.001)$.

\subsection{Multivariate Regression Analysis}

Multivariate regression analyses with Stepwise method were conducted to further explore the association among demographic variables, trait forgiveness and interpersonal relationship, among which gender, major, origin, siblings number and trait forgiveness were set as predicative variables, while social support and interpersonal disturbance as dependent variables. Results showed that(1) trait forgiveness, major, siblings numbers and gender could predict social support significantly and together they could account for $11.1 \%$ of the variation in social support $\left(R^{2}=0.111\right)$; (2) trait forgiveness, origin, major and siblings numbers could predict interpersonal disturbance significantly and together they could account for $16.0 \%$ of the variation in interpersonal disturbance $\left(R^{2}=0.16\right)$; (3)in the above two regression analyses, trait forgiveness was the best predictive variable, and it could account for $7.3 \%$ and $11.9 \%$ of the variation in social support and interpersonal disturbance (See Table 1).

Table 1 Results of Multivariate Regression Analysis

\begin{tabular}{|c|c|c|c|c|c|c|c|}
\hline DV & IV & $\boldsymbol{R}$ & $R^{2}$ & $\Delta \boldsymbol{R}$ & $\boldsymbol{F}$ & Beta & $t$ \\
\hline \multirow{4}{*}{$\begin{array}{l}\text { Social } \\
\text { Support }\end{array}$} & Trait forgiveness & 0.271 & 0.073 & 0.073 & 41.712 & 0.268 & 6.465 \\
\hline & major & 0.296 & 0.088 & 0.015 & 25.297 & -0.102 & -2.357 \\
\hline & Siblings numbers & 0.319 & 0.101 & 0.013 & 19.729 & -0.124 & -2.979 \\
\hline & Gender & 0.333 & 0.111 & 0.010 & 16.281 & 0.101 & 2.332 \\
\hline \multirow{4}{*}{$\begin{array}{l}\text { Interpersonal } \\
\text { Disturbance }\end{array}$} & Trait forgiveness & 0.345 & 0.119 & 0.119 & 71.159 & -0.360 & -8.942 \\
\hline & Origin & 0.377 & 0.142 & 0.023 & 43.615 & -0.105 & -2.298 \\
\hline & Major & 0.390 & 0.152 & 0.010 & 31.366 & 0.109 & 2.699 \\
\hline & Siblings numbers & 0.400 & 0.160 & 0.008 & 24.903 & 0.100 & $2.197^{\circ}$ \\
\hline
\end{tabular}


IJASOS- International E-Journal of Advances in Social Sciences, Vol. V, Issue 14, August 2019

Note. ${ }^{*} p<0.05,{ }^{* *} p<0.01,{ }^{* \star *} p<0.001 ; \mathrm{IV}=$ independent variable; $\mathrm{DV}=$ dependent variable

\subsection{Pearson Correlation Analysis}

The correlations among trait forgiveness, aggressive behavior and interpersonal relationship were calculated (see Table 2). Results showed that all variables significantly correlated with each other (all $p<0.001)$ : (1) Aggressive behavior correlated negatively with trait forgiveness and social support, positively with interpersonal disturbance; (2) Trait forgiveness correlated positively with social support and negatively with interpersonal disturbance; (3) Social support correlated negatively with interpersonal disturbance. That is to say, individuals who are more forgiving generally have less aggressive behaviors and better interpersonal relationships with others.

\section{Table 2 Correlations among trait forgiveness, aggression and interpersonal relationship}

\begin{tabular}{|l|l|l|l|l|}
\hline & Aggression & $\begin{array}{l}\text { Social } \\
\text { Support }\end{array}$ & $\begin{array}{l}\text { Interpersonal } \\
\text { Disturbance }\end{array}$ & $\begin{array}{l}\text { Trait } \\
\text { forgiveness }\end{array}$ \\
\hline Aggression & 1.00 & & & \\
\hline Social Support & -0.28 & 1.00 & & \\
\hline Interpersonal Disturbance & $0.43^{\prime \prime \prime}$ & $-0.37^{\prime \prime \prime}$ & 1.00 & \\
\hline Trait forgiveness & $-0.40^{\prime \prime \prime}$ & $0.27^{\prime \prime}$ & -0.35 & 1.00 \\
\hline
\end{tabular}

Note. ${ }^{*} p<0.05,{ }^{* *} p<0.01,{ }^{* * *} p<0.001$

\subsection{Mediating Effects Testing}

Based on the comparison of various testing methods of mediating effects, Wen (2004, 2014) proposed a composite testing procedure, which was better than any single testing method in terms of type 1 and type 2 error rates and could be used to test both partial and full mediating effects. According to Wen's newly proposed procedure, three regression equation models were run to estimate the relationships among aggressive behaviors, trait forgiveness and social support and to generate the statistics needed to test the mediating effects (see Table 3). In equation \#1, trait forgiveness was regressed on social support to estimate the regression coefficient $c\left(\beta_{c}=0.266, p<0.001\right)$. In equation \#2, trait forgiveness was regressed on aggressive behaviors to estimate the regression coefficient a $\left(\beta_{a}=-0.398, p<0.001\right)$.In equation \# 3 , both trait forgiveness and aggressive behaviors were regressed on social support to estimate the regression coefficient $c^{\prime}$ and $b\left(\beta_{c^{\prime}}=0.185, \beta_{b}=-0.203, p s<0.001\right)$. The regression coefficients a and b were significant, indicating that aggressive behavior was the mediator between trait forgiveness and social support, while the regression coefficients $c$ and c' were significant, indicating that aggressive behavior had a partial mediating effect between trait forgiveness and social support(Wen, Chang, Hau, \& Liu, 2004; Wen \& Ye, 2014). In present study, the coefficient measuring the total effect of trait forgiveness on social support was 0.266 in equation \# 1. When aggressive behavior was introduced in equation \# 3 , the coefficient was reduced to 0.185 , indicating that aggressive behavior mediated the relationship between trait forgiveness and social support. The decrease of $0.08(0.266-0.185)$ in the standardized coefficient represented the mediated effect, and the ratio of mediating effects on total effects was $30.4 \%\left(E f f e c t_{m}=a b / c=0.398 \times 0.203\right.$ $\div 0.266=0.304)$. The similar mediating effect of aggressive behavior was also found between trait forgiveness and interpersonal disturbance (see Table 4). The mediating effects of aggressive behavior between trait forgiveness and interpersonal relationship (including social support and interpersonal disturbance) could be depicted through a path diagram (see Fig. 1).

Table 3 Mediating effect of AB between TF and SS

\begin{tabular}{|l|l|l|l|l|l|l|l|}
\hline Equation & $\mathrm{IV} \rightarrow \mathrm{DV}$ & $R$ & $R^{2}$ & $\Delta R$ & $F$ & Beta & $t$ \\
\hline$(1) \mathrm{Y}=\mathrm{cX}+\mathrm{e}_{1}$ & $\mathrm{TF} \rightarrow \mathrm{SS}$ & 0.266 & 0.070 & 0.070 & 40.273 & 0.266 & 6.346 \\
\hline$(2) \mathrm{M}=\mathrm{aX}+\mathrm{e}_{2}$ & $\mathrm{TF} \rightarrow \mathrm{AB}$ & 0.398 & 0.158 & 0.158 & 99.590 & -0.398 & -9.979 \\
\hline \multirow{2}{*}{$(3) \mathrm{Y}=\mathrm{c}^{\prime} \mathrm{X}+\mathrm{bM}+\mathrm{e}_{3}$} & $\mathrm{AB} \rightarrow \mathrm{SS}$ & 0.277 & 0.077 & 0.077 & 43.918 & -0.203 & -4.529 \\
\cline { 2 - 8 } & $\mathrm{TF} \rightarrow \mathrm{SS}$ & 0.325 & 0.105 & 0.028 & 31.162 & 0.185 & 4.132 \\
\hline
\end{tabular}

Note. ${ }^{* \star \star} p<0.001$; IV = independent variable; $\mathrm{DV}=$ dependent variable; $\mathrm{AB}=$ aggressive behavior; SS = social support; TF = Trait forgiveness 
Table 4 Mediating effect of AB between TF and ID

\begin{tabular}{|c|c|c|c|c|c|c|c|}
\hline Equation & $\mathrm{IV} \rightarrow \mathrm{DV}$ & $R$ & $R^{2}$ & $\Delta R$ & $F$ & Beta & $t$ \\
\hline (4) $Y=c X+e_{1}$ & $\mathrm{TF} \rightarrow \mathrm{ID}$ & 0.347 & 0121 & 0.121 & $72.804^{*}$ & -0.347 & -8.533 \\
\hline (5) $M=a X+e_{2}$ & $T F \rightarrow A B$ & 0.398 & 0.158 & 0.158 & 99.590 & -0.398 & -9.979 \\
\hline \multirow[t]{2}{*}{ (6) $Y=c^{\prime} X+b M+e_{3}$} & $\mathrm{AB} \rightarrow \mathrm{ID}$ & 0.437 & 0.191 & 0.191 & $125.123^{\circ}$ & 0.355 & $8.517^{* *}$ \\
\hline & $\mathrm{TF} \rightarrow \mathrm{ID}$ & 0.476 & 0.227 & 0.036 & 77.641 & -0.207 & -4.959 \\
\hline
\end{tabular}

Note. ${ }^{* * *} p<0.001$; IV = independent variable; $\mathrm{DV}=$ dependent variable; $\mathrm{AB}=$ aggressive behavior; ID = interpersonal disturbance; TF = Trait forgiveness

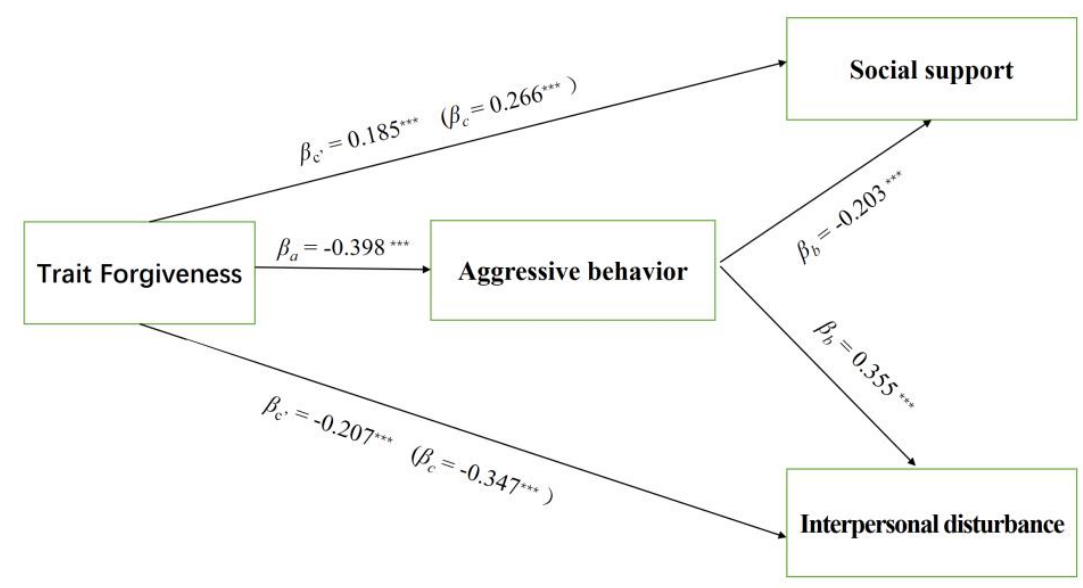

Fig.1 Path program of mediating effects

\section{DISCUSSION}

In this study, the gender difference of trait forgiveness was found, namely, the total score of female students was significantly higher than that of male students, which was consistent with most researches at home and abroad (Brown, 2003; Li, 2011). The differences may be related to the different levels of empathy, the different thinking styles or the different tendencies in moral choice and moral judgment between male and female.

As for the relationship between trait forgiveness and interpersonal relationship, we hypothesized that two paths existed: direct path and indirect path. On one hand, trait forgiveness may directly promote harmonious relationship and reduce interpersonal disturbance. On the other hand, trait forgiveness may indirectly influence interpersonal relationship through some mediating variables. The results of this study can be used to verify the existence of these two paths.

In present study, the results of independent sample t-test, partial correlation analysis and regression analysis strongly demonstrated the existence of direct path. Forgiveness, with a nature of prosocial altruism and selfprotection, can help individuals establish and maintain good interactions, improve and repair damaged relationships (Finkel, Rusbult, Kumashiro, \& Hannon, 2002), increase individuals' satisfaction to interpersonal relationships(McCullough, 2000), especially in family (Maio, Thomas, Fincham, \& Carnelley, 2008)and marriage (McNulty, 2008).

The partial mediating effect of aggressive behavior between trait forgiveness and interpersonal relationship was also found in present study. As we know, aggressive behavior, which is closely connected with personality traits, can be seen as an important evaluating indicator and influencing factor of interpersonal relationship. Those who have high score of trait forgiveness often have the following characteristics: emotionally stable, friendly, altruistic, compassionate, outgoing, sociable and popular. When offences occur, though experiencing the negative emotions caused by hurt, the offended with high trait forgiveness often choose rational ways rather than aggressive behaviors to solve the problem in order to maintain psychological or interpersonal harmony. They show sympathy for the offenders, drop negative emotions, such as hatred, anger and fear, restore the peace of mind and avoid the spread of hurt by means of forgiveness. The individuals who are more forgiving usually have better interpersonal relationship, more social support and less interpersonal disturbance. As for the offended with low trait forgiveness, on the contrary, they may bear a grudge against the offender, meditate on the offences, pass the pain on to the offender or the others. Pushed by negative emotions, they may aggress or revenge against the people 
around them, which may lead to the deterioration of interpersonal relationship, including the lack of social support and the long-term interpersonal disturbance.

\section{CONCLUSION}

(1) Significant gender differences existed in trait forgiveness, that is, trait forgiveness of female students was significantly higher than that of male students.

(2) Trait forgiveness positively correlated with social support and negatively with interpersonal disturbance.

(3) Trait forgiveness could predict interpersonal relationship significantly.

(4) Aggressive behavior served as a partial mediator variable between trait forgiveness and interpersonal relationship.

\section{REFERENCE LIST}

Barlett, C. P., \& Anderson, C. A. (2012). Direct and indirect relations between the Big 5 personality traits and aggressive and violent behavior. Personality and Individual Differences, 52(8), 870-875.

Berry, J. W., Worthington, E. L., Parrott, L., O Connor, L. E., \& Wade, N. G. (2001). Dispositional forgivingness: Development and construct validity of the Transgression Narrative Test of Forgivingness (TNTF). Personality and Social Psychology Bulletin, 27(10), 1277-1290.

Brose, L. A., Rye, M. S., Lutz-Zois, C., \& Ross, S. R. (2005). Forgiveness and personality traits. Personality and Individual Differences, 39(1), 35-46.

Brown, R. P. (2003). Measuring individual differences in the tendency to forgive: Construct validity and links with depression. Personality and Social Psychology Bulletin, 29(6), 759-771.

Buss, A. H., \& Perry, M. (1992). The aggression questionnaire. Journal of Personality and Social Psychology, 63(3), 452-459.

Card, N. A., \& Little, T. D. (2006). Proactive and reactive aggression in childhood and adolescence: A metaanalysis of differential relations with psychosocial adjustment. International Journal of Behavioral Development, 30(5), 466-480.

de Almeida, R. M., Cabral, J. C., \& Narvaes, R. (2015). Behavioral, hormonal and neurobiological mechanisms of aggressive behavior in human and nonhuman primates. Physiology and Behavior, $143,121-135$.

Ferguson, C. J., \& Beaver, K. M. (2009). Natural born killers: The genetic origins of extreme violence. Aggression and Violent Behavior, 14(5), 286-294.

Finkel, E. J., Rusbult, C. E., Kumashiro, M., \& Hannon, P. A. (2002). Dealing with betrayal in close relationships: Does commitment promote forgiveness? Journal of Personality and Social Psychology, 82(6), 956-974.

Hawley, P. H., Little, T. D., \& Card, N. A. (2007). The allure of a mean friend: Relationship quality and processes of aggressive adolescents with prosocial skills. International Journal of Behavioral Development, 31(2), 170-180.

Karremans, J. C., Van Lange, P. A. M., Ouwerkerk, J. W., \& Kluwer, E. S. (2003). When forgiving enhances psychological well-being: The role of interpersonal commitment. Journal of Personality and Social Psychology, 84(5), 1011-1026.

$\mathrm{Li}, \mathrm{X}$. (2011). Study on the forgiveness and its correlation with mental health among college students. Modern Preventive Medicine, 38(14), 2763-2766.

Maio, G. R., Thomas, G., Fincham, F. D., \& Carnelley, K. B. (2008). Unraveling the role of forgiveness in family relationships. Journal of Personality and Social Psychology, 94(2), 307-319.

McCullough, M. E. (2000). Forgiveness as human strength: Theory, measurement, and links to well-being. Journal of Social and Clinical Psychology, 19(1), 43-55.

McCullough, M. E., Pargament, K. I., \& Thoresen, C. E. (2000). The Psychology of forgiveness: History, conceptual issues, and overview In M. E. McCullough, K. I. Pargament, \& C. E. Thoresen (Eds.), 
Forgiveness: Theory, research, and practice. New York: Guilford Press.

McCullough, M. E., Rachal, K. C., Sandage, S. J., Worthington, E. L., Brown, S. W., \& Hight, T. L. (1998). Interpersonal forgiving in close relationships: II. Theoretical elaboration and measurement. Journal of Personality and Social Psychology, 75(6), 1586-1603.

McCullough, M. E., \& Witvliet, C. V. O. (2002). The psychology of forgiveness. In C. R. E. Snyder \& S. J. Lopez (Eds.), Handbook of positive psychology (pp. 446-455). New York: Oxford University Press.

McCullough, M. E., Worthington, E. L., \& Rachal, K. C. (1997). Interpersonal forgiving in close relationships. Journal of Personality and Social Psychology, 73(2), 321-336.

McNulty, J. K. (2008). Forgiveness in marriage: Putting the benefits into context. Journal of Family Psychology, 22(1), 171-175.

Sharpe, J. P., \& Desai, S. (2001). The revised Neo Personality Inventory and the MMPI-2 Psychopathology Five in the prediction of aggression. Personality \& Individual Differences, 31(4), 505-518.

Tse, W. S., \& Yip, T. (2009). Relationship among dispositional forgiveness of others, interpersonal adjustment and psychological well-being: Implication for interpersonal theory of depression. Personality and Individual Differences, 46(3), 365-368.

Wang, X., Wang, X., \& Ma, H. (1999). Manual of mental health rating scale. Beijing: Chinese Mental Health Journal Publisher.

Watkins, D. A., Hui, E.K., Luo, W., Regmi, M., Worthington, E. L., Hook, J. N., \& Davis, D. E. (2011). Forgiveness and interpersonal relationships: a Nepalese investigation. Journal of Psychology and Theology, 151(2), 150-161.

Wen, Z., Chang, L., Hau, K.-T., \& Liu, H. (2004). Testing and application of the mediating effects. Acta Psychologica Sinica, 36(5), 614-620.

Wen, Z., \& Ye, B. (2014). Analyses of mediating effects: The development of methods and models. Advances in Psychological Science, 22(5), 731-745.

Yang, X., Li, W., \& Zheng, X. (2019). Development of trait forgiveness questionnaire for college students. Psychology: Techniques and Application, 7(8): 472-484.

Yu, J. J., Lim, G. O., \& Gamble, W. C. (2016). Big five personality traits and physical aggression between siblings in South Korea: an actor-partner interdependence analysis. Journal of Family Violence, 32(2), 1-11.

Zheng, R. (1999). Psychological diagnosis of college students. Jinan: Shandong Education Press.

Zimet, G. D., Powell, S. S., Farley, G. K., Werkman, S., \& Berkoff, K. A. (1990). Psychometric characteristics of the multidimensional scale of perceived social support. Journal of Personality Assessment, 55(3-4), 610-617. 